\title{
Correlação de métodos geofísicos e verificação de melhor arranjo eletródico para determinar a profundidade do topo rochoso no Setor Noroeste de Brasília/DF
}

Guilherme Meirelles da Motta de Figueiredo Gaudêncio'; Welitom Rodrigues Borges²;

Fabio Augusto dos Santos 1 ; Arthur Domenici Pinheiro

1 Discentes do Curso de Graduação em Geofísica do IG/UnB

2 Docente do Instituto de Geociências da Universidade de Brasília

Copyright 2014, SBGf - Sociedade Brasileira de Geofísica

Este texto foi preparado para a apresentação no VI Simpósio Brasileiro de Geofísica, Porto Alegre, 14 a 16 de outubro de 2014. Seu conteúdo foi revisado pelo Comite Técnico do VI SimBGf, mas não necessariamente representa a opinião da SBGf ou de seus associados. É proibida a reprodução total ou parcial deste material para propósitos comerciais sem prévia autorização da SBGf.

\section{Resumo}

This work presents the correlation of Ground Penetrating Radar and electrical resistivity data in order to determine the depth of bedrock in the region. The electric resistivity profiles were acquired with dipole-dipole, Wenner and Wenner-Schlumberger arrays, with a spacing between the electrodes of 2 meters. The GPR data were acquired with antennas of 250 and $700 \mathrm{MHz}$. The electrode array that enabled the best resolution was the dipole-dipole, and both antennas GPR enabled the imaging of the top of the quartzite layer. The two methodologies were able to accurately determine the discontinuity in quartzitic basement of the region, besides verifying the shallower depth of the foundation, occurring at 0,5 m depth.

\section{Introdução}

A geofísica aplicada tornou-se essencial para a exploração mineral, mapeamento geológico, monitoramento de áreas contaminadas e projetos de engenharia, uma vez que minimiza os custos com sondagens. O uso dessas metodologias em estudos geotécnicos auxilia na determinação de estruturas geológicas (falhas, fraturas, etc.), camadas de materiais inconsolidados, interferências (tubos, galerias, fiações elétricas, etc.), e profundidade do impenetrável.

Dentre os métodos geofísicos comumente usados para estudos geotécnicos estão o Ground Penetrating Radar (GPR) e a eletrorresistividade.

Esse resumo apresenta os resultados de testes com arranjos eletródicos e seções de GPR, desenvolvidos em uma região onde inexistem afloramentos rochosos, com o objetivo de verificar qual é a profundidade do topo rochoso na região do Setor Militar Urbano (SMU) de Brasília, DF.

O SMU localiza-se na cidade de Brasília/DF, nas coordenadas UTM da zona 23S $187096.786 \mathrm{~N}$ e 8255188.684 E (Figura 1).

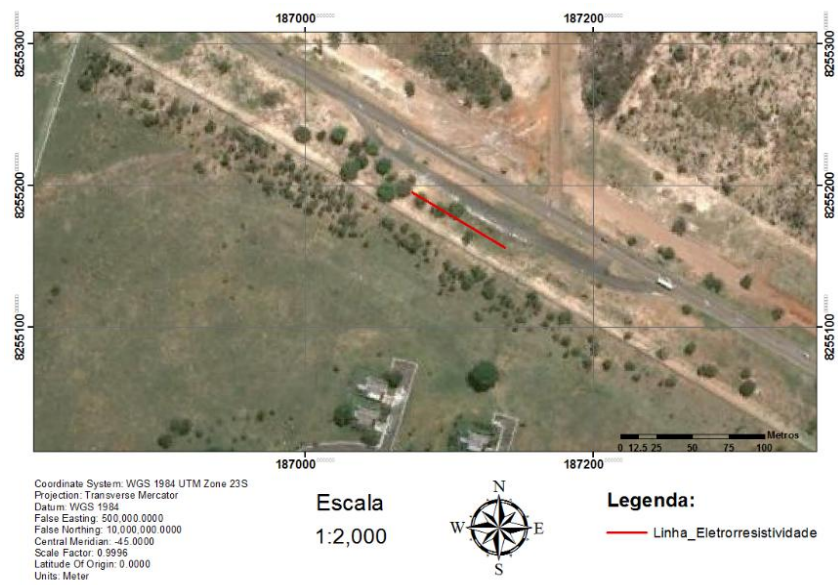

Figura 1 - Mapa de localização do perfil geofísico na cidade de Brasília, DF.

A área de pesquisa é dentro do novo bairro chamado de Setor Noroeste, última região disponível para construção dentro do perímetro tombado de Brasília. O novo bairro possui 200 hectares de extensão, com projeto para conter 220 prédios residenciais e 40 mil moradores.

\section{Contexto Geológico}

A unidade geológica presente na área pertence é o metarritmito arenoso (R3) do Grupo Paranoá. Esta unidade é caracterizada por intercalações de bancos decimétricos a métricos de quartzitos e materiais pelíticos (Figura 2). Localmente observam-se pacotes de até $10 \mathrm{~m}$ de espessura que se destacam do conjunto rítmico, a espessura total desse conjunto pode alcançar até $90 \mathrm{~m}$ (Campos, 2013). 


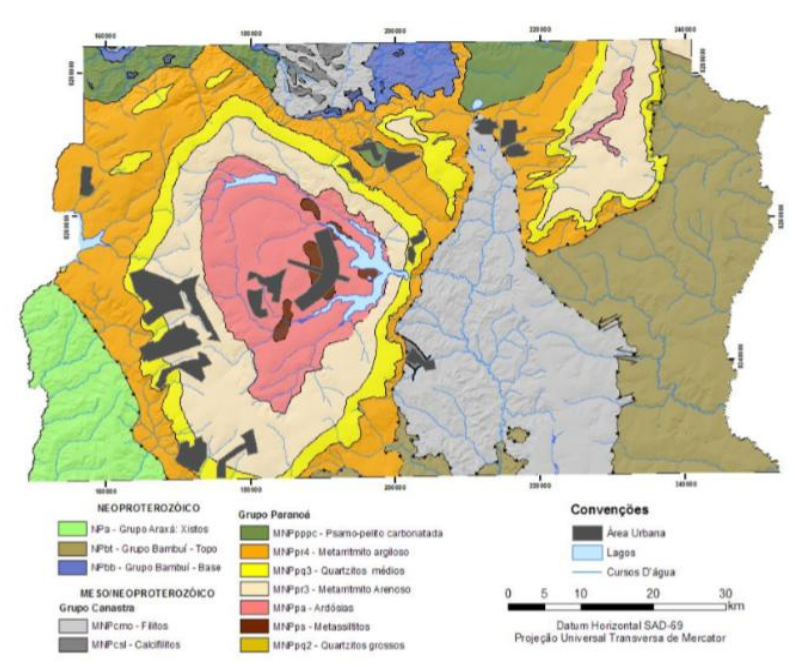

Figura 2 - Mapa geológico do Distrito Federal. (Campos et al, 2013).

\section{Metodologia}

O presente trabalho usou duas metodologias geofísicas, a eletrorresistividade e o GPR.

ELETRORRESISTIVIDADE: este método consiste na verificação dos potenciais desenvolvidos nos materiais, a partir da propagação de uma corrente (I) injetada no solo por intermédio de um par de eletrodos (denominados de A e B) e a medida da diferença de potencial (V) resultante da passagem desta corrente e através de outro par de eletrodos situados nas proximidades (denominados $\mathrm{M}$ e $\mathrm{N}$ ). A geometria dos dipolos A B e $\mathrm{M}$ $\mathrm{N}$ no momento da medida definem o fator geométrico $\mathrm{K}$, dado por (Eq. 1):

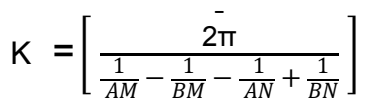

A resistividade elétrica aparente ( $\rho$ ) é então calculada através da Eq. 2:

$$
\rho a=K \cdot \frac{\Delta \mathrm{V}}{\mathrm{I}}
$$

Os quatro eletrodos podem assumir qualquer disposição geométrica sobre a superfície do terreno, e são denominados de arranjos. A escolha do melhor arranjo para um levantamento de campo depende do tipo de estrutura a ser mapeada, da sensibilidade do medidor de resistividade e do nível de ruído de background.

Entre as características consideradas de um arranjo estão: a profundidade de investigação, a sensibilidade do arranjo para alterações verticais e horizontais de resistividade em subsuperfície, a cobertura de dados e a intensidade do sinal (LOKE, 2004).
GROUND PENETRATING RADAR: Esse método baseiase na reflexão de pulsos eletromagnéticos. Estes pulsos são irradiados em direção ao meio por antenas emissoras. A energia emitida sofre, ao encontrar contrastes de impedância elétrica, o fenômeno físico da reflexão e retorna à superfície onde é captada pela antena receptora. A partir da diferença de tempo entre emissão e retorno dos campos eletromagnéticos é possível obter informações das propriedades eletromagnéticas do meio em subsuperfície. Assim, é gerada uma imagem de alta resolução do meio.

\section{Aquisição e Processamento dos dados}

A técnica de aquisição utilizada no campo foi a de caminhamento elétrico. Realizou-se um perfil com 72 metros de comprimento, usando-se 36 eletrodos com espaçamento de $2 \mathrm{~m}$, e quatro arranjos eletródicos. Com o arranjo dipolo-dipolo adquiriram-se 502 pontos em 26 níveis de investigação. Com o arranjo pólo-dipolo obtiveram-se 559 pontos em 26 níveis de profundidade, e neste arranjo o eletrodo de corrente A ficou a $30 \mathrm{~m}$ de distância do início do perfil (infinito). Com o arranjo Wenner coletaram-se 197 pontos em 11 níveis de investigação. Com 0 arranjo Wenner-Schlumberger obtiveram-se 302 pontos em 17 profundidades distintas. O equipamento na aquisição de dados de resistividade elétrica foi o SYSCAL PRO 72(Iris Instruments). A filtragem dos dados de campo foi realizada no software PROSYS II, e em posteriormente modelados com 0 software RES2DINV.

O equipamento utilizado para aquisição dos perfis GPR foi o Detector Duo, com antena de dupla frequência (250 - $700 \mathrm{Mhz}$ ) fabricado pela IDS. Adquiriu-se um perfil de GPR no mesmo local do perfil de eletrorresistividade. Os parâmetros da aquisição foram 1024 amostras por traço, janela temporal de 250 ns e velocidade do meio para a conversão tempo-profundidade de $0,1 \mathrm{~m} / \mathrm{hs}$ (obtida através da informação de uma galeria próxima à área). Desenvolveu-se todo o processamento no software ReflexW (correção estática, filtro 1D, ganho, e conversão de tempo em profundidade).

\section{Resultados}

O resultado obtido com o GPR evidencia o topo da camada de quartzito a partir de 0,6 metro de profundidade na parte inicial do perfil (Figura 3a). A partir de 30 de distância a rocha é registrada abaixo de 4,2 metros de profundidade.

As seções de resistividade elétrica registram valores de resistividade entre 1000 e 15000 Ohm.m. Notam-se em todas as seções dois principais horizontes geoelétricos. Uma zona resistiva mais rasa, comum a todas seções, diminui lateralmente devido a mudança na profundidade do embasamento na região (figuras $\mathbf{3 b}, \mathbf{3 c}$, $\mathbf{3 d}$ e $\mathbf{3 e}$ ).

Em todas as seções nota-se que o solo é menos espesso até a distância de 18 metros (menos que $0,5 \mathrm{~m}$ de 
profundidade), e a partir deste ponto o solo possui uma espessura média de 4 metros.

Os arranjos Wenner (WN) e Wenner-Schlumberger (WS) apresentam aproximadamente o mesmo resultado, a diferença é que o WS investiga 2 metros a mais em profundidade que o WN (figuras $3 c$ e $3 d$ ).

Os resultados obtidos com o arranjo pólo-dipolo (PD) possibilitaram 0 imageamento de uma maior profundidade em função do eletrodo (infinito, Figura 3e).

A seção obtida com o arranjo dipolo-dipolo (DD) mostra um contraste mais efetivo entre o solo e a rocha, deste modo torna-se o mais eficiente na identificação desta interface.

\section{Conclusões}

Os contrastes evidenciados com a inversão dos dados de resistividade elétrica coincidem os obtidos com o GPR.

O GPR mostra maior resolução das imagens em função da maior amostragem espacial deste método.

Os resultados de resistividade elétrica confirmam um subsolo muito resistivo (acima de 1000 Ohm.m), que é o melhor meio para o GPR.

O arranjo eletródico que possibilitou o melhor imageamento do substrato rochoso foi o DD, seguido dos arranjos WS, WN e PD.

\section{Agradecimentos}

Os autores agradecem aos alunos do Instituto de Geociências: João Marcos, Samuel Machado, Bruno Mazão e Lucas Lopes, pela colaboração nas etapas de campo.

Ao Laboratório de Geofísica Aplicada da UnB pelo suporte na logística de campo, no empréstimo dos equipamentos, e na disponibilização dos softwares utilizados nesse estudo.

\section{Referências}

CAMPOS JEG; DARDENNE, MA; FREITAS-SILVA, FH; MARTINS-FERREIRA, MAC. 2013. Geologia do Grupo Paranoá na porção externa da Faixa Brasília. Braz. J. Geol., vol.43 no.3 São Paulo set. 2013.

LOKE, MH. 2004. A practical guide to 2-D and 3-D surveys. Electrical imaging surveys for environmental and engineering studies. 136p. Disponível em: http://www.geoelectrical.com/coursenotes.zip, acessado em 14/05/2014 

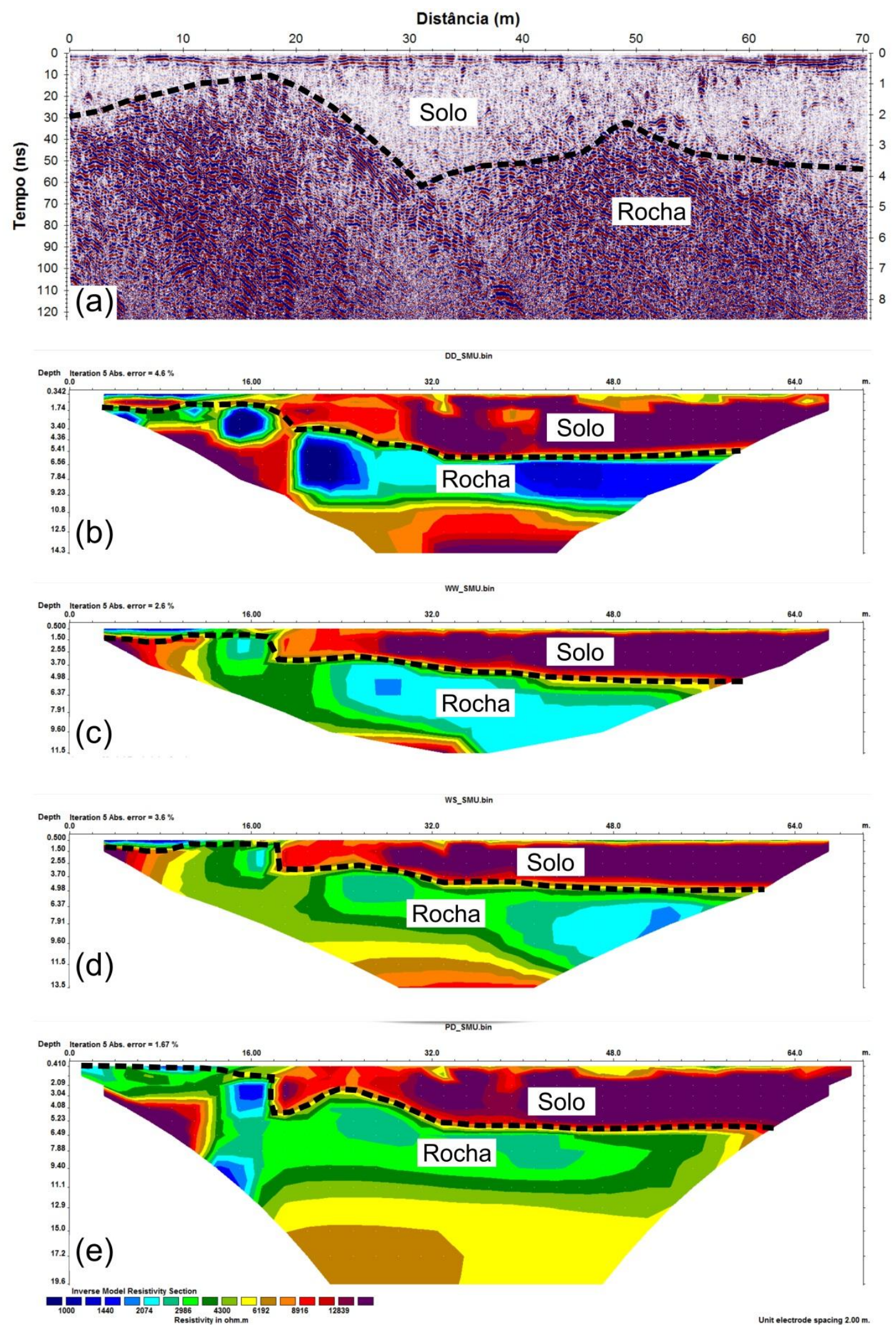

Figura 3 - Seções geofísicas desenvolvidas no local pesquisado com as interpretações sobrepostas: (a) Seção de GPR; Modelos de resistividade elétrica obtidos com os arranjos (b) Dipolo-dipolo, (c) Wenner, (d) Wenner-Schlumberger, e (e) Pólo-dipolo. 